\title{
Violência discursiva: uma abordagem sociológica sobre a construção de inimigos na República Federal Alemã
}

\author{
Arim Soares do Bem ${ }^{1}$
}

\begin{abstract}
Resumo: "Inimificação" é o processo de construção de inimigos e relaciona-se à instrumentalização de modelos dicotômicos que promovem práticas de exclusão de indivíduos e grupos sociais. Este artigo tem o objetivo de discutir aspectos relacionados à construção de inimigos na República Federal Alemã, colocando em relevo o contexto discursivo que marcou o processo de unificação, no interior do qual o chamado "Asyl-Debatte" (debate sobre o asilo político) ganhou destaque entre os anos de 1989 e 1992 e promoveu uma proliferação discursiva favorável à produção de consensos antidemocráticos, levando à introdução de cláusulas restritivas na legislação. Ao explicitar o conteúdo e as formas de instrumentalização do "outro" no interdiscurso social da RFA, o artigo discute o papel da ideologia como mecanismo central de construção identitária e de delimitação e fixação de fronteiras.
\end{abstract}

Palavras-chave: Inimificação; Construção de inimigos na República Federal Alemã; Violência discursiva.

Discursive violence: a sociological approach on the construction of enemies in the German Federal Republic

Abstract: "Inimification" is the process of construction of enemies and becomes related it the instrumentalisation of dicotomic models that promote of exclusion of individuals and social groups practical. This article has the objective to argue aspects related to the construction of enemies in the German Federal Republic, placing in relief the discursive context that marked the unification process, in the interior of which the call "Asyl-Debatte" (debate on the asylum politician) gained prominence enters the years of 1989 and 1992 and promoted a discursive proliferation favorable to the production of antidemocratic consensuses, leading to the introduction of restrictive clauses in the legislation. When to explicit the content and the forms of instrumentalisation of the

${ }_{1}^{1}$ Doutor em Sociologia, professor do Instituto de Ciências Sociais da Universidade Federal de Alagoas, E-Mail: arimdobem@yahoo.com.br

Latitude, Vol. 1, n'2, pp.47-65, 2007. 
"other" in social interdiscourse of the RFA, the article argue the paper of the ideology as central mechanism of identity construction and delimitation and setting of borders.

Key-words: inimification; Construction of enemies in the German Federal Republic; discursive violence.

\section{Introdução}

O holocausto não teria existido se não tivesse sido precedido pela construção de uma barreira moral entre os perpetradores e suas vítimas. A oposição que se estabelece entre os que pertencem e os que são excluídos separa o "verdadeiro" do "falso", o "belo" do "feio", o "bom" do "mau", eliminando dúvidas (BAUMAN, 1991, p. 24). Enquanto fenômeno o processo de construção de inimigos atravessa a história da humanidade. A fixação de fronteiras entre o "dentro" e o "fora", mas também entre o "em cima" e o "embaixo", é de fato constitutiva das sociedades. Elas fixam e administram as fronteiras construídas, separando a ordem do caos. Outredades emergem necessariamente dessa operação e as categorias relacionam-se dialeticamente com os elementos coesivos instituídos e/ou funcionais para a reprodução da ordem dominante. Se na idade média tais fronteiras se regulavam a partir da mediação religiosa (SOARES DO BEM, 2009 e 2008), no colonialismo e no industrialismo a "raça", em suas diferentes formas de construção, passou a ser importante critério de distinção e separação, assim como nos séculos XIX e XX "nação", "povo" e "cultura" emergiram para regular as diferenças a partir de novas necessidades (RADTKE, 1991, p. 80; BALIBAR, 1990). Sendo categorias dinâmicas, juntam-se e se separam em diferentes contextos históricos discursivos, sobrepondo-se ou se justapondo em complexas combinações (SOARES DO BEM, 1994)2.

Se o fenômeno da construção de inimigos é, pois, tão antigo, o conceito que lhe serve de base descritiva e analítica nem é suficientemente delimitado, como salienta Seyfarth (2006), nem se faz presente em todos os contextos. Nossa preocupação não será aqui desenvolver uma discussão com vistas à obtenção de maior precisão conceitual, senão explorar as várias facetas do conceito, fazendo preferencialmente uso daquele que se consolidou no contexto alemão: "Feindbildkonstruktion" (construção de imagens de inimigos). Segundo Nuscheler (1995, p. 251), "inimificação descreve geralmente um padrão de interpretação em relação a outras pessoas ou grupos de pessoas (principalmente minorias), nações, povos, Estados ou ideologias, aos quais se associam, com

${ }^{2}$ Neste texto chamo a atenção para as especificidades na instrumentalização das diferenças étnico-"raciais" em alguns países como Alemanha, França, Inglaterra e Brasil.

Latitude, Vol. 1, n'2, pp.47-65, 2007. 
base em uma divisão dicotômica do mundo (dicotomia, dualismo), idéias, atitudes e sentimentos negativos" (tradução nossa).

Há que se fazer distinção entre imagens de inimigos sistêmicos ("Systemfeindbilder"), que ocupam o quadro de referências das ciências políticas e se relacionam mais especificamente à construção de inimigos sistêmicos (como capitalismo versus comunismo, etc.) e imagens de inimigos ("Feindbilder") relacionados à construção de inimigos em perspectiva etno-sociológica, sinalizando distinções entre grupos "In" e "Out" (SOARES DO BEM, 1998). A idéia de imagem associada à construção de inimigos aproxima-nos da definição de Dieckmann (apud WAGENLEHNER, 1989, p. 6), segundo o qual com o conceito de "Feindbild" (imagens de inimigos) não se entende "o inimigo ou o opositor em si, mas uma terceira coisa, algo que se interpõe entre ele e nós mesmos, imagem, que, como todas as imagens é composta de uma quantidade de componentes, com as quais o objeto freqüentemente muito pouco ou quase nada tem a ver" (tradução nossa).

O terceiro elemento que se interpõe entre os inimificadores e suas vítimas, pois, são as imagens e estas têm pouca ou nenhuma relação com o grupo instrumentalizado. A produção de imagens destrutivas funciona a partir de associações que se autonomizam e podem tanto perder a relação com o "eu" como com o "outro". Adorno (1973), por exemplo, demonstrou que o ódio aos judeus tornava-se tão mais profundo entre seus entrevistados quanto maior era a desproporção entre culpa e punição, de modo que a manutenção do ódio podia ser vista como uma tentativa "de comprovar para si e para os outros que se estava agindo corretamente" (p. 144, tradução nossa). A dissociação entre o comportamento anti-semita e o objeto empírico do ódio manifesta-se também em argumentos, como aquele comentado por Sartre (1954, p. 11): "Você vê, deve haver algo de errado com os judeus: eles me irritam fisicamente" (tradução nossa). Sartre (1954, p. 11), questiona a arbitrariedade de tal argumento ao examiná-lo a partir de uma constução hipotética: "Deve haver qualquer coisa com o tomate, pois tenho horror de comê-lo". Não é, pois, a experiência que engendra a noção negativa de "judeu", mas é o próprio "judeu" que ilumina a experiência au contraire: "Se não existisse o judeu, o anti-semita o inventaria" (SARTRE, 1954, p. 14, tradução nossa).

Jovens Skinheads da periferia de São Paulo por nós entrevistados comportaram-se de modo semelhante (SOARES DO BEM, 2005). A construção de imagens negativas de judeus no discurso desses jovens parecia estar submetida ao imperativo de uma "lei racional", autônoma e exterior, diretamente associada a uma eterna culpa, da qual os judeus não podem se desvencilhar. No contexto da unificação Alemã, jovens alemães "ocidentais" e "orientais" referiram-se igualmente ao "ódio" como uma força irresistível que os impelia à violência (física ou discursiva) contra estrangeiros, migrantes e exilados (SOARES DO BEM, 2008a; 2005; 1998; 1994; 1993; 1992). Leiprecht (1990), descreve detalhadamente o processo da funcionalização

Latitude, Vol. 1, n'2, pp.47-65, 2007. 
subjetiva (Subjektive Funktionalisierung) de estrangeiros e migrantes por jovens trabalhadores na Alemanha e privilegia tanto a análise do referido automatismo que intitulou seu livro a partir da fala de um de seus entrevistados: "...da baut sich já in uns ein Hass auf..." ("...aí então se constrói um ódio em nós..."). Evidencia-se, assim, que esses jovens sentem-se meros portadores do "ódio", atribuindo a condição de sujeito à própria sociedade, entidade situada "acima" e "fora" deles - única instância a ser responsabilizada pelas conseqüências de seus atos.

Constatamos que a Outredade não se encontra, pois, substancialmente no "outro", mas acima de tudo naquele que assim o constrói. Bielefeld (1991, p. 9, tradução nossa) é enfática a esse respeito: "Não se pode falar abstratamente sobre o estranho e sobre o estrangeiro. Se a fala é especificada, a gente fala sobre si mesmo. O estranho concretiza-se no autor da fala". À vista disso, se quisermos conhecer o "outro", temos que procurá-lo em seus arquitetos e engenheiros. Essa constatação impõe a necessidade do estabelecimento de diferenciações fundamentais entre os conceitos de inimificação ("Feindbildkonstruktion"), estereótipo e preconceito.

\section{Preconceito, inimificação e estereótipo: sutis diferenças}

Schäfer e Six (1978) argumentam que o preconceito, na linguagem cotidiana, é compreendido como um "comportamento de avaliação de pessoas ou grupos sobre fatos percebidos como incorretos em virtude de generalizações ou rigidez e tido como impróprio em relação aos valores que contém. Em muitos casos, depende do próprio ponto de vista a validade do juízo como preconceito" (p. 13, tradução nossa).

A inadequação da noção de preconceito salta aos olhos, ao sugerir que o comportamento "pré-conceituoso" possa ser compreendido como um desvio da realidade do objeto fixado e fazendo supor que uma aprendizagem correta, "objetiva", desse objeto, pudesse salvá-lo da instrumentalização. São visíveis as desastrosas tentativas de produzir juízos "válidos" sobre propriedades de determinados grupos sociais, principalmente de minorias: sejam exemplarmente citados os disparates socialdarwinistas provocados por testes de coeficientes de inteligência. A submersão do jornalista alemão Wallraff (1985) nos porões da sociedade alemã, incorporando a figura idealizada de um turco chamado Ali Sinirlioglu, partiu exatamente da necessidade de conhecer "objetivamente", pela experiência, a realidade vivida pelos migrantes turcos em seu país. Valendo-se da caricatura bastante grotesca do personagem que criou (quanto "pré-conceito" já não é necessário para se criar um personagem pública e institucionalmente discriminado?), Wallraff nada mais fez com sua imersão na verdade do "outro" senão reproduzir a "verdade" do próprio pré-conceito: os turcos são sujos, rudes, maltratados, 'desempoderados", mal pagos, analfabetos, falam pessimamente a língua alemã (como deve ter sido difícil para ele, genuíno

Latitude, Vol. 1, n'2, pp.47-65, 2007. 
representante da maioria étnica, falar o alemão arrastado de Ali!) e pobres - afinal os turcos se encontram "ganz unten" (muito lá embaixo), como se depreende do título da edição alemã de seu livro.

De modo diametralmente oposto, a lista de propriedades dos "alemães" parece resultar de verdadeira simetria entre posição de poder e imagem positiva: "cientificamente orientados, trabalhadores, persistentes, inteligentes e sistemáticos" (LEIPRECHT, 1990, p. 76). Os resultados da investigação de Wagner (1982) sobre juízos da maioria alemã a respeito dos turcos, a partir dos quais ele identificou uma correlação entre "alta inteligência", bom nível de educação formal e baixos preconceitos étnicos, só podem induzir à formação de "falsas consciências" sobre a realidade da sociedade alemã, levando ao escamoteamento de sua estrutural separação étnica e da universalidade de suas práticas de exclusão. Com efeito, o argumento de que haveria uma correlação necessária entre (baixa) posição social e "pré-conceitos" étnicos (HENNIG, 1984) já foi suficientemente criticado a partir da década de 80. Bergmann e Leggewie (1993), por exemplo, ao investigarem a posição social de atores de extrema direita, corroboram a posição defendida por Oskar Negt de que o extremismo de direita estaria sedimentado no "centro" da sociedade alemã e que esses grupos radicais não seriam compostos (apenas) por elementos das camadas baixas. É tendo em vista tal constatação que Hopf (1994) postulou a inclusão das elites políticas, esfera pública, polícia, justiça e burocracia estatal como instâncias relevantes para a análise genética do extremismo de direita e Van Dijk (1991) desenvolveu detalhada investigação sobre a função do discurso da elite para a reprodução do racismo. Jäger e Link (1993, p. 9) acrescentam que "apesar de todo o perigo direto causado por uma minoria racista militante, o maior perigo vem do 'centro' político, ou seja, do consenso silencioso entre a elite hegemônica do CDU e do SPD".

Com efeito, esta temática é objeto de intenso debate desde os anos 1930 na Alemanha. "Extremismo do centro" é um termo que foi cunhado nesta época por Theodor Geiger para descrever a origem pequeno-burguesa do movimento nacionalsocialista e introduzido na sociologia americana por Lipset em 1958 para caracterizar o fascismo como movimento da classe média (Cf. KRAUSHAAR, 1994, p. 27). Butterwegge (1996, p. 118 e 119), argumenta que a concentração histórica no pólo "extremo" do espectro político sinaliza um desvio do "centro" e a retirada de sua responsabilidade no desenvolvimento político de direita, no país. Através da instrumentalização das posições de "esquerda" e "direita", essencialmente representadas como "antidemocráticas", o "centro" podia, assim, colocar-se acima de toda crítica. Jaschke (1991, p. 46) complementa essa idéia quando afirma que a oposição estabelecida entre democracia e extremismo pressupõe erroneamente a existência de um comportamento democrático das instituições, contra o caráter antidemocrático do extremismo. Isso teria levado também os pesquisadores alemães

\footnotetext{
${ }^{3}$ Respectivamente, Christlich Demokratische Union - CDU e Sozialdemokratische Partei - SPD.
}

Latitude, Vol. 1, n'2, pp.47-65, 2007. 
ao tratamento do extremismo de direita e de esquerda como opositores da ordem estatal e não como um fenômeno social enraizado na sociedade.

Diante do exposto, evidencia-se que a legalidade do "pré-conceito" parece, assim, inquestionavelmente comprometida e sua força explicativa definitivamente condenada ao fracasso. Além desses aspectos, o preconceito contribui enormemente para naturalizar as relações sociais, situando a "falsa consciência" dos preconceituosos no plano individual, e, com isso, bloqueando a análise da estrutura social e dos mecanismos supra-individuais (institucionais) da exclusão. Saliente-se que entre o preconceito e a inimificação (Feindbildkonstruktion) existem semelhanças, principalmente com relação ao déficit de realidade que marca ambos os conceitos (Cf. OSTERMANN, 1977, p. 113). No entanto Seyfarth (2006, p. 4) afirma que o preconceito não contém necessariamente o elemento hostil ("feindselig"), podendo mesmo se servir de uma construção positiva do "outro", como se verificou a propósito da imagem dos alemães como "inteligentes", "disciplinados" e "cientificamente orientados". Se há em ambos os conceitos um elemento comum, que é a falsa atribuição, o elemento hostil da inimificação sustenta-se no processo de racionalização, que o distingue decididamente do preconceito. Por esta razão a inimificação (Feindbildkonstruktion) não é pré-conceito (Vor-Urteil), mas juizo (Urteil) (SEYFARTH, 2006, p. 9). Ostermann (1977, p. 132) argumenta que a racionalização implica a construção de uma superestrutura de argumentos racionais que têm como objetivo justificar o comportamento excludente. Apesar de entendermos como frutífera a utilização, por Ostermann, do conceito de racionalização, distanciamo-nos da autora quando se refere à racionalização como resposta a demandas colocadas pela necessidade de satisfação de necessidades (meramente) psíquicas. Voltaremos à questão.

A inimificação (Feindbildkonstruktion) tem ainda uma extraordinária diferença com relação ao "pré-conceito" por ser, não apenas deficitária, mas criadora de realidade. Ostermann (1977) argumenta que "se uma pessoa tem a impressão completamente equivocada de que a outra é sua inimiga, isso vai influenciar o seu comportamento diante dela. O suposto inimigo vai perceber esse comportamento e reagir de modo compatível. Esta reação será interpretada pela primeira pessoa como confirmação de sua (falsa) percepção e a levará a reagir novamente como se reage diante de um inimigo" (p. 103, tradução nossa).

Neste sentido pode-se dizer que a inimificação tem o caráter de uma Selffulfilling Prophecy. Ela é imediatamente relevante do ponto de vista da ação. Provocar a atitude negativa do outro pode ser parte de uma estratégia de racionalização que concorre para legitimar a própria violência. A agressão pode ser também legitimada reportando-se a um passado supostamente marcado por ataques provocados pelo "outro", diante dos quais a tolerância finalmente chega ao seu limite. Hochbruck e Kröger (1992, p.11) salientam que desde a Declaração da Independência

Latitude, Vol. 1, n'2, pp.47-65, 2007. 
dos Estados Unidos da América essa tem sido a retórica de guerra mais usual e que foi dentro dessa tradição que se inseriu G. Bush ao declarar guerra a Saddam Hussein. Utilizando-se de imagens e motivos tradicionais e suportado por forte esquema mediático, além de personalizar o conflito em torno da figura do presidente iraquiano Bush legitimou a guerra acusando o "inimigo" de ser o único responsável pelo fracasso das conversações de paz: "Enquanto o mundo esperava, Saddam Hussein violava, explorava e saqueava um pequeno país. Ele submeteu o povo do Kuwait a atrocidades indescritíveis, e entre mutilados e assassinados - crianças inocentes" (HOCHBRUCK; KRÖGER, 1992, p. 15, tradução nossa).

A inimificação de Saddam Hussein como infrator, alienado moral e imprevisível opositor da paz foi tão mais efetiva diante da nação, à qual Bush se dirigiu antes do início dos ataques, quanto mais intensos os seus apelos eram adornados por fraseologias cristãs: "Enquanto o mundo rezava para a paz, Saddam preparava a guerra" (1992, p. 17, tradução nossa). A nação americana e a população mundial foram situadas em oposição ao "inimigo" através de referências feitas por Bush a um "nós" que tanto escamoteava barreiras internas (de classe, gênero, etnia, etc.) como externas (nacionais): "Lamentavelmente, agora nós acreditamos que somente a força vai fazê-lo (Saddam) deixar (o poder)" (1992, p. 14, tradução e grifo nossos). Que esta retórica era uma retórica de poder e que ela tinha um papel histórico para a construção de uma "nova ordem mundial", as palavras do próprio Bush não deixam nenhuma dúvida: "Se nós formos bem sucedidos, e nós seremos, nós teremos uma chance real nesta nova ordem mundial" (1992, p. 14, tradução e grifos nossos)4.

O conceito alemão "Feindbild" é um compósito constituído pela junção de dois substantivos (inimigo + imagem) e este joga muito bem com a dimensão "artesanal" da construção de inimigos, resultando sempre de um processo peculiar de seleção. A inimificação pressupõe a existência de um ator que se enuncia enquanto escultor de imagens pregnantes (KÖHNKE et al., 2001, p. 149), as quais não apenas descrevem o objeto, mas o fixa de um modo específico pelo olhar. "A condição prévia para a imagem é a visão", diz Barthes (1984, p. 84) a propósito da construção da imagem fotográfica. Por esta razão a imagem enquanto código visual é mais do que mera ilustração do real. Satjukow e Gries (apud SEYFARTH 2004, p. 28), distinguem entre imagens de percepção (Wahrnehmungsbilder), que têm caráter residual e não se fixam de modo pregnante no imaginário e imagens de memória (Gedächtnisbilder), as quais, mesmo na ausência do objeto estão suficientemente fixadas e podem predispor a comportamentos política e/ou socialmente relevantes. Tais condições internas (innere Zustände), segundo Huhnke (1993, p. 237), favorecem a geração de realidades simbólicas que suprem as estruturas emocionais (Gefühlsstrukturen), desencadeando

${ }^{4} \mathrm{Na}$ tradução da frase original "When we are successful, and we will be, we have a real chance at this new world order", mantivemos o pronome "nós", que poderia ser evidentemente suprimido, para explicitar a sua significação contextual.

Latitude, Vol. 1, n'2, pp.47-65, 2007. 
no sujeito monólogos internos e os amalgamando a modelos interpretativos sociais (Gesellschaftliche Deutungsmuster). Vê-se, pois, que a construção de inimigos (Feindbildkonstruktion) mobiliza todo um arsenal de signos, metáforas e símbolos, que funcionam como um cartão de entrada na estrutura emocional dos sujeitos e produzem efeitos ideológicos e cognitivos, levando-os a um comportamento determinado - entenda-se: violento - diante do objeto (Cf. EDELMAN, 1976).

O estereótipo, por sua vez, descreve o processo de simplificação e redução de complexidade do real, direcionando a atenção para determinadas classes de informações e eliminado outras, além de generalizar as classes selecionadas de informações a um determinado grupo social ou a uma determinada situação. Petersen e Schwender (2009, p. 13) salientam que o estereótipo não contém necessariamente juízos negativos ou positivos e, neste sentido, distancia-se tanto do preconceito como da inimificação, embora possa ser, instrumentalmente, parte constitutiva dos processos descritos por esses conceitos.

\section{O Sistema Sincrônico de Símbolos Coletivos}

Link (1982) divide os campos dos discursos especializados, nas modernas culturas industrialistas, em três segmentos: 1) ciências naturais; 2) ciências humanas e 3) discursos especializados dominados interdiscursivamente. Dos discursos especializados constituem-se nas relações cotidianas tipos de falas (Redetypen) que expõem saberes culturais seletivos, aos quais denomina interdiscurso. O interdiscurso, que Link também chama de "burburinho flutuante" (fluktuierendes Gewimmel) - já que não é regulado e sistematizado como os discursos especializados -, reintegra de modo popular o complexo sistema da divisão do trabalho dos discursos especializados, tornando-os acessíveis a amplos segmentos sociais. O interdiscurso é sustentado, segundo Link, por um sistema sincrônico de símbolos coletivos. Segundo ele, "Símbolos coletivos possuem uma alta capacidade de reprodução cultural [...] e enorme capacidade parafrástica: pode-se resumir num único símbolo coletivo uma mensagem inteira" (LINK, 1982, p. 79, tradução nossa). Através de regras associativas chamadas por Link de catacrese $^{5}$, os símbolos coletivos possibilitam a realização da sincretização de diferentes experiências sociais.

\footnotetext{
5 A catacrese é a aplicação de termo figurado em decorrência da inexistência de termo próprio, como por exemplo: "as pernas da mesa". Link o utiliza para salientar a proliferação e sobreposição de significações no interdiscurso social.
}

Latitude, Vol. 1, n'2, pp.47-65, 2007. 
O conhecimento da funcionalidade de um símbolo exige a exploração de suas regras semânticas associativas e isto significa que também o contexto histórico-social no interior do qual as representações interagem precisa ser levado em consideração. Foi a partir da observação de tal exigência que Link reconheceu, no início dos anos 1980, que nas regras associativas dos discursos desencadeados pelo "Manifesto de Heidelberg", a ameaçadora "enchente de turcos" era identificada como uma forma de desequilíbrio ecológico. O sistema de símbolos coletivos projeta-se de modo específico, em cada contexto histórico, como uma rede discursiva e contribui para a construção de mitos, indicando, ao mesmo tempo, a necessidade de uma ação política normalizadora (Normalisierungsbedarf). Link (1993, p. 24) afirma que desde o final da guerra fria a categoria "normalidade" tem dominado maciçamente a consciência pública das sociedades ocidentais, colocando-se mesmo, enquanto dispositivo de regulação, no lugar de idéias emancipatórias e utópicas. Apesar da explosão (Durchbruch) discursiva da categoria "normalidade", Link identifica a ausência de uma clara separação categorial entre norma, validade normativa (Normgeltung) e normatividade, de um lado, e entre normal, normalidade e normalização, de outro.

Ao contribuir para a construção de uma história do normalismo, Link identifica três momentos cruciais para a sua cristalização nas modernas sociedades: $\mathrm{O}$ primeiro impulso ter-se-ia constituído no bojo do movimento analisado por autores como Georges Canguilhem, Michel Foucault e Robert Castel, entre outros, e está relacionado ao campo da medicina, de onde se desenvolveram concepções sobre saúde e higiene. A este campo se acoplaram concepções e práticas de intervenção da psiquiatria e psicologia, bem como da psicologia social; o segundo impulso está relacionado ao normalismo técnico-industrial, ocupado pragmaticamente pelo campo da economia, ergonomia e ecologia, entre outros. Os campos dominados por esses dois momentos compõem-se de dispositivos estatísticos, produção maciça de dados e clara definição de indicadores de fronteira (Grenzwerte), bem como do estabelecimento de zonas de tolerância; o terceiro impulso do normalismo descreve, não mais o funcionamento de setores específicos, mas tem extensão e função integradoras, abrangendo o espaço interdiscursivo hegemônico do campo social, das relações cotidianas e da esfera política (LINK, 1995, p. 25).

Alguns anos após a queda do muro de Berlim, o espaço mediático foi marcado, na Alemanha unificada, pelo acirrado debate sobre o asilo político, principalmente entre os anos de 1991 e 1994. Os meios de comunicação acentuavam sobremaneira os perigos do supostamente crescente abuso da legislação e do Estado do bem-estar social por parte de inúmeros migrantes e fugitivos que chegavam ao país. Foi um período de extrema violência contra estrangeiros, praticada preponderantemente por jovens do sexo masculino e que refletia um grande consenso de parte considerável da população naquele momento de grande instabilidade sócio-econômica e política. Esse clima fora reforçado pela classe política com as restrições adicionadas à legislação de estrangeiros no verão de 1992 (SOARES DO BEM, 2008a). Ficou visível, neste contexto, a

Latitude, Vol. 1, n'2, pp.47-65, 2007. 
constituição de uma associação sincrônica de significados no interdiscurso hegemônico sobre a migração e o asilo político: as imagens de "enchentes de exilados" (Asylantenflut) articulavam-se às questões relacionadas à rede social, ao superestranhamento (Überfremdung) provocado pela suposta extrapolação de indicadores de normalidade e ao crescimento da criminalidade. A "enchente de exilados", simbolizada pela imagem do "barco cheio", foi "espontaneamente" codificada como o câncer da sociedade.

\section{Ideologia: ação, responsabilidade, "enredamento"}

As imagens pregnantes (KÖHNKE, 2001) funcionam como material protoideológico para a construção de inimigos. Haug (1993, p. 52) chama de "protoideologisches Material" a todas as formas e forças coesivas, como modelos de interpretação compartilhados, discursos e comportamentos, imagens, preferências e aversões que são potencialmente ideologizáveis. Embora circulem de modo difuso pelo interdiscurso social, essas imagens remetem ao discurso total (Gesamtdiskurs) de uma dada formação social. Leontjew (1982), em sua teoria da atividade (Tätigkeitstheorie), faz uma distinção importante entre significação social (Gesellschaftliche Bedeutung) e sentido individual (persönlicher Sinn) para captar, de um lado, a complexa relação entre indivíduo e sociedade e, de outro, remeter à objetividade da significação que permite o acesso ao discurso total sem incorrer na psicologização e no mecanicismo. O discurso total (Gesamtdiskurs) insere-se na esfera da significação objetiva (objektive Bedeutung), enquanto o sentido subjetivo (Subjektiver Sinn) é de natureza individual.

A operação (Operation) é uma categoria de mediação importante que se insere entre a significação objetiva e o sentido subjetivo. Sendo materializada pela ação, a operação é parte constitutiva da estrutura da atividade humana, figurando dinamicamente como canalizadora da necessidade (Bedürfnis) - no interior da qual a motivação está objetivada - e do objetivo (Ziel). A operação é, pois, uma atividade que permite antecipar um resultado submetido a um objetivo pré-estabelecido. A exposição da teoria da atividade de Leontjew presta-se exemplarmente à refutação da argumentação de Ostermann (1977, p. 132) com relação ao entendimento de que a racionalização responde a demandas de ordem meramente psíquicas. Entende-se aqui que projeções psíquicas são parte constitutiva de todo processo de construção de inimigos, mas distanciamo-nos de toda psicologização que reduz tais projeções a uma natureza psíquica essencial, como é usual na psicologia tradicional.

A dimensão psíquica não é aqui negligenciada enquanto "interioridade vivida" (erlebte Innerlichkeit), mas tampouco canonizada e equiparada a um psiquismo imanente (Cf. HOLZKAMP, 1985, p. 46). A psicologia tradicional, segundo

Latitude, Vol. 1, n'2, pp.47-65, 2007. 
Leiprecht (1990, p. 87), perde de vista a participação na construção das relações sociais por indivíduos-atores e os reduz à condição unilateral de seres externamente determinados. A redução da atividade humana a um mecanismo de projeção psíquica leva inevitavelmente à suspensão da responsabilidade. Mesmo em situações pessoais de graves limitações, salienta Holzkamp (1990, p. 355), o sujeito é sempre responsável pelos seus atos e a condição de sujeito deve ser vista como genuína especificidade da existência humana. Poder-se-ia objetar que tal interpretação tende a um horizonte racionalista. No entanto, a responsabilização dos sujeitos não implica que estes ajam dominados por uma consciência onipresente. É para evitar tal equívoco que Jäger e Link (1993, p. 143-144) introduziram no debate um conceito relativizador, notadamente o conceito de "enredamento" (Verstrickung), que explicita o movimento de identificação dos indivíduos com as relações e discursos socialmente hegemônicos. Eles podem realizar conscientemente operações tendo em vista a satisfação de necessidades e tendo objetivos claros para alcançar determinados resultados e, no entanto, estarem "enredados" em relações e discursos de poder e dominação.

Cabe, nesse sentido, uma breve reflexão sobre o conceito de ideologia que adotamos, na perspectiva do Projekt Ideologie-Theorie (1986). Evitando qualquer associação mecânica e metafísica com esse conceito polissêmico, Haug (1993, p. 48) compreende a ideologia não como um sistema de visões de mundo, atitudes e valores, mas como algo que se manifesta concretamente em aparelhos e práticas que têm por finalidade regular e organizar interesses antagônicos. Para captar a dialética relação entre estrutura e ação, Haug estabelece uma distinção entre o campo ideológico (Das Ideologische) e as ideologias concretas (konkrete Ideologien). O ideológico é compreendido como um nexo socializador vertical, sendo o Estado compreendido como poder ideológico que, além do exercício da violência "legítima", realiza a função de organizar consensos. Na estrutura material do ideológico, que descreve a socialização ideal "de cima", operam as ideologias concretas (HAUG, 1979, p. 182), na forma de pensamentos e ações específicos. As ideologias concretas adquirem conteúdos específicos decorrentes de condições históricas e sociais. Foi o relevo dado às condições históricas específicas da Alemanha no contexto da unificação que nos possibilitou compreender o papel das ideologias concretas (entre as quais se colocam aquelas relacionadas ao processo de construção de inimigos) para a produção de consensos conservadores. A tentativa de vários jovens de localizarem e instrumentalizarem seus "inimigos" num cenário marcado por novas configurações sociais demonstra como as ideologias reagem sensivelmente às dinâmicas políticas.

À socialização ideal "de cima" (ideelle Fremdvergesellschaftung), o Projekt Ideologie-Theorie (1986) opõe dois conceitos: o conceito de auto-socialização (Selbstvergesellschaftung) e o de socialização cultural ou horizontal (horizontale Vergesellschaftung). Na forma da auto-socialização está implícita a apropriação ou ampliação do controle sobre as condições de existência. A dimensão cultural é analiticamente separada do ideológico para permitir diferenciar forças coesivas

Latitude, Vol. 1, n'2, pp.47-65, 2007. 
inespecíficas que não operam com a mesma funcionalidade, mas Haug (1993, p. 53) salienta que "empiricamente o cultural é tão pouco puro como o ideológico [...] e na vida cotidiana misturam-se as mais diferentes forças e fenômenos". Quando os indivíduos são chamados, "de cima", para a ordem e acatam os seus apelos, eles o fazem dando sustentação a ela, "de baixo", com as próprias mãos (selbsttätig) e isso seguramente por que a "oferta" ideológica é acompanhada do cálculo subjetivo sobre vantagens individuais. A fala de um jovem trabalhador alemão com orientação política de direita e entrevistado por Held, Horn, Leiprecht e Markavis (1992) evidencia a funcionalidade das ideologias concretas: "Du musst so handeln, dass Du Gewinn machst" (você precisa agir de modo a tirar proveito).

Com efeito, Held et al (1992, p. 26) constataram que a identificação de jovens trabalhadores alemães com as relações e cultura dominantes foi central para a orientação política de direita encontrada entre os mesmos. Entre eles, a cultura dominante foi percebida eminentemente do ponto de vista do desempenho econômico e a "consciência nacional" (Nationalbewusstsein) marcada por um grande vazio histórico, cultural e político. Held et al (1992, p. 28) afirmam que a efetividade da economia de mercado capitalista é acompanhada de tipos de cognição e ação específicos que implicam a instrumentalização dos "outros" a partir de critérios pragmáticos. Argumentam também que estes tipos de cognição e de ação podem levar a orientações de direita se passam a dominar de modo completo o horizonte político e a esfera privada dos indivíduos - como é o caso dos jovens por eles entrevistados.

A investigação que desenvolvemos entre jovens alemães ocidentais, orientais e jovens de origem estrangeira nascidos em Berlin chegou a idênticos resultados. Critérios utilitaristas evidenciaram-se em quase todos os processos de construção de fronteiras (Grenzziehungsprozesse), tanto na relação dos jovens alemães ocidentais para com os orientais (e vice-versa) como na relação dos jovens de origem estrangeira para com os jovens alemães ocidentais e orientais. A monetarização das relações interpessoais fez com que esses jovens percebessem seus interesses preponderantemente no plano econômico. Isso coloca em evidência processos relacionados à (re)privatização de riscos sociais, à desregulação e à racionalização da economia. A esses aspectos soma-se a influência dos meios de comunicação, que tratam cotidianamente questões sociais embasados em cifras e impregnam o interdiscurso social com argumentos fundados em esquemas do tipo custoutilizabilidade (SOARES DO BEM, 1998, p. 290).

A campanha do jornal tablóide diário Bild 6 contra exilados políticos, no outono de 1991, pode ser citada como exemplo de funcionalização de símbolos coletivos na

${ }^{6} \mathrm{O}$ atual jornal Bild (Imagem), anteriormente chamado de Bild-Zeitung (Jornal de imagens) foi fundado em 1952 por Axel Springer e é reconhecido por sua modelagem marcada pela mistura de histórias criminais, conservadorismo político e métodos sensacionalistas.

Latitude, Vol. 1, n'2, pp.47-65, 2007. 
República Federal Alemã. Na ocasião, o jornal estampou em suas páginas uma "Nova Série" (Neue Serie) sobre o tema do asilo político, com reportagens diárias. A série recebeu um sugestivo título: "Exilados em revista - quem deve pagar por isso?"7. Ao lado da manchete colocando em relevo a expressão "exilados", a imagem de uma massa composta por rostos nebulosos sugeria uma invasão incontrolável de requerentes de asilo político. Segundo a documentação feita sobre a campanha por Quinkert e Jäger (1991), a característica comum dessa série de reportagens foi atribuir aos requerentes o abuso do direito de asilo e fazer referências às suas estranhas tradições (Fremde Sitte), bem como ao colapso das ofertas de imóveis, ao desemprego e aos custos sociais mobilizados - irônico é saber que desde 1982 o Parlamento Federal (Bundestag) aprovou medidas instituindo para os exilados acomodações coletivas ("containers") e retirando dos mesmos o direito ao trabalho (Cf. JÄGER, S., 1992, p. 10). A restrição institucional ao direito de exercer legalmente o trabalho colocava os exilados sob a mira da acusação pública de inflacionarem o mercado ilegal de trabalho (Schwarzarbeit) e pressionarem para baixo os salários, ao passo que o fato de estarem prescritos como "moradores de containers" favorecia a desmoralização de sua condição, naturalizada enquanto socialmente degradada. A fronteira material e moral fixada pelas relações jurídico-institucionais podia, assim, fazer com que a relação da maioria com a minoria fosse interpretada e vivenciada como uma relação de concorrência (Cf. BUTTERWEGGE, 1994, p. 44).

A campanha inimificadora do jornal Bild e de outros órgãos da imprensa, mas também os discursos, as práticas da elite política e a estabilidade interdiscursiva e excludente da esfera social e cotidiana levaram a uma "onda" de violência contra exilados e migrantes, cujo ponto culminante foi alcançado nos anos de 1992 e 1993. Somente no ano de 1992 foram registrados 2584 atos de violência com motivação extremista e vários casos de mortes (Cf. WICHERT, 1995, p. 99). A materialidade dos discursos reside no fato de provocar e predispor à ação, diferentemente do que supunha o behaviorista Skinner (1957) ao afirmar que "meras palavras não quebram ossos". Enquanto os ataques às moradias dos exilados ocorriam diariamente, grande parte da imprensa estilizava as ocorrências como conseqüência da situação sócioeconômica do leste e com isso declarava o extremismo como um problema dos "burros" alemães orientais (Cf. PFENNIG, 1993, p. 25; WICHERT, 1993, p. 29), além de interpretar os ataques como decorrência de um incontrolável e fatal automatismo. Da perspectiva dos agressores, situados num contexto de ausência de autênticos canais para a articulação de interesses de "baixo" para "cima" e imobilizados diante da possibilidade de reclamarem seus reais direitos à integração, restava apenas o sentimento de que a "política" somente reagia de modo desejável às suas expectativas após a prática da violência - o que, aliás, se confirmou com a inclusão de cláusulas restritivas na legislação sobre o asilo político.

\footnotetext{
${ }^{7}$ Em alemão: “Asylanten im Revier - wer soll das bezahlen?".
}

Latitude, Vol. 1, n'2, pp.47-65, 2007. 


\section{Considerações finais}

Se na teoria política liberal, desde os séculos XVII e XVIII e, mais tardiamente, em determinadas correntes do pensamento social, a opinião pública tem sido preponderantemente compreendida a partir de sua função ordenadora da vida social e, portanto, como mecanismo de controle de poder e de sustentação de avanços normativos da democracia (Cf. BORGES, 2008, p. 1), a relação aqui exposta e discutida entre opinião pública e política cimenta uma articulação que se presta à produção de consensos eminentemente antidemocráticos. Esse amálgama entre "os de cima" e "os de baixo" produziu um "deslizamento para a direita" (Rechtsruck), reconfigurando as forças políticas em torno de uma normalização já reclamada no início da década de 1980. Seidel-Pielen e Farin (1992, p. 13) referem-se ao apelo de Alfred Dregger, em 1982, para que os alemães saíssem finalmente da sombra de Hitler e se tornassem "normais". O clima desencadeado, no período, pelo Heidelberger Manifest era favorável a essa normalização autoritária e pode ser responsabilizado como um dos pilares funcionais para a emergência da chamada Nova Direita. Decorrente de um processo de desnazificação realizado somente ao nível do discurso e, ainda assim, de modo parcial e ambíguo (Cf. SOARES DO BEM, 1993), o revisionismo histórico encontrou, no contexto da unificação alemã, forte terreno para assentar bases estáveis e refutar continuidades com o passado nacional-socialista. Sintomático é que poucos anos depois, notadamente em meados de 1986, eclodiu o chamado "Historikerstreit" (disputa sobre a história), que contribuiu para suprimir (ficticiamente) as fronteiras entre a elite política, meios de comunicação, segmentos intelectuais e o "povo" alemão no contexto de reconstrução de fronteiras que caracterizou a unificação alemã e, com isso, garantiu a construção de consensos eminentemente anti-democráticos.

Pode-se falar, de fato, da existência de uma dupla funcionalidade das formas ideológicas: elas são tanto funcionais do ponto de vista da dominação como subjetivamente. Em termos da dominação, elas são funcionais na medida em que pressupõem o reconhecimento das relações de poder e o desejo particularista de delas participar, satisfazendo a própria necessidade - ao preço da exclusão do outro; são subjetivamente funcionais na medida em que prometem - e em situações determinadas promovem - melhorias nas condições de existência dos indivíduos. A ação restritiva (restriktives Handeln), que se materializa quando os indivíduos se colocam reprodutivamente ao lado das relações de poder, contrariamente à capacidade de ação ampliada (Verallgemeinerte Handlungsfähigkeit), contém sempre um momento de auto-inimizade (Selbstfeindschaft). Aquilo que deve ser assegurado através de arranjos com as relações de poder dominantes implica inevitavelmente a instrumentação do outro. Holzkamp (1983, p. 377), argumenta, nesse sentido, que a instrumentalização do outro significa sempre uma forma de auto-instrumentalização: "na tentativa de me assegurar através do controle do outro, sou lançado cada vez mais contra

Latitude, Vol. 1, n'2, pp.47-65, 2007. 
mim mesmo e me torno cada vez mais impotente diante de minhas indisponíveis condições de existência" (tradução nossa). Apropriar poder, na forma da expropriação do poder do Outro, é, portanto, uma forma de auto-desempoderamento (Selbstentmächtigung) (Cf. OSTERKAMP, U., 1996).

Contra a inimificação e aos seus processos desumanizadores, deve opor-se uma nova ética a ser construída, bastante distinta daquela ética liberal que se deixou colonizar pela religião, pela ciência, pela tecnologia e por interesses particularistas, tornando-se instrumento de regulação e de exclusão (Cf. SANTOS, B. S., 2007). Mas esse é um assunto que só poderá ser discutido detalhadamente em outra oportunidade.

\section{Bibliografia}

ADORNO, T. W. Minima Moralia. Reflexionen aus dem beschädigten Leben. Berlin/Frankfurt am Main: Suhrkamp Verlag, 2001.

BALIBAR, E. Gibt es einen Neo-Rassismus? In: BALIBAR, E.; WALLERSTEIN, I. (Hrsg.). Rasse Klasse Nation. Ambivalente Identitaeten. Hamburg/Berlin: Argument, 1990.

BARTHES, R. A câmara clara. Rio de Janeiro: Nova Fronteira, 1984.

BAUMAN, Z. Moderne und Ambivalenz. In: BIELEFELD (Hrsg.). Das Eigene und das Fremde. Neuer Rassismus in der alten Welt? Hamburg: Junius, p. 23-50, 1991.

BERGMANN, J.; LEGGEWIE, C. Die Täter sind unter uns. Beocbachtungen aus der Mitte Deutschlands. In: Kursbuch 113. Berlin: Rowolt Verlag, p. 7-37, 1993.

BIELEFELD, U. Einleitung. In: BIELEFELD (Hrsg.). Das Eigene und das Fremde. Neuer Rassismus in der alten Welt? Hamburg: Junius, p. 9-19, 1991.

Bíblia Sagrada. Tradução do Padre Antonio Pereira de Figueiredo. Rio de Janeiro: Edição Barsa, p. 495-496, 1964.

BORGES, S. Opinião Pública, Media e Cidadania: as manifestações pela paz nas vésperas da II Guerra do Golfo. Anais do XXXI Congresso Brasileiro de Ciências da Comunicação. Natal: Intercom, p. 1-12, 2008.

BUTTERWEGGE, C. Extremismus der Mitte und/oder völkischer Nationalismus? In: JÄGER, M.; JÄGER, S. (Hrsg.). Baustellen. Beiträge zur Diskursgeschichte deutscher Gegenwart. Duisburg: Diss, p. 117-128, 1996.

BUTTERWEGGE, C. Gewalt an Schulen: Geschichte - Erscheinungsformen Gegenstrategien. Problemübersicht und Literaturbericht. In: Jäger, S. (Hrsg.).

Latitude, Vol. 1, n'2, pp.47-65, 2007. 
Aus der Werkstatt: Anti-Rassistische Praxen. Konzepte. Erfahrungen. Forschung. Duisburg: Diss, p. 39-53, 1994.

EDELMAN, M. Politik als Ritual. Die symbolische Funktion staatlicher Institutionen und politischen Handelns. Frankfurt/M: Campus Verlag, 1976.

HAUG, W. F. Elemente einer Theorie des Ideologischen. Hamburg/Berlin: Das Argument, 1993.

HELD, J. et al. “...Du musst so handeln, dass Du Gewinn machst...". Empirische Untersuchungen und theoretische Überlegungen $\mathrm{zu}$ politisch rechten Orientierungen jugendlicher Arbeitnehmer. Duisburg: Diss, 1992.

HENNIG, E. Wie wird man rechtsextremer Jugendlicher in der Bundesrepublik Deutschland? In: Bundeszentrale für politische Bildung (Hrsg.). Extremismus und Schule. Daten, Analysen und Arbeitshilfen zum politischen Rechts- und Linksextremismus, Bd. 212, Bonn, p. 151-170.

HOPF, W.Rechtsextremismus von Jugendlichen: kein Deprivationsproblem? In: Zeitschrift für Sozialisationsforschung und Erziehungssoziologie, Heft 3, p. 196.

JÄGER, S.; LINK, J. Die vierte Gewalt. Rassismus und die Medien. Einleitung. In: JÄGER, S.; LINK, J. (Hrsg.). Die vierte Gewalt. Rassismus und die Medien. Duisburg: Diss, 1993, p. 7-20.

JÄGER, S. BrandSätze. Rassismus im Alltag. Duisburg: Diss, 1992.

JASCKE, H. G. Streitbare Demokratie und innere Sicherheit. Grundlagen, Praxis und Kritik. Opladen: Leske und Budrich, 1991.

KÖHNKE, K. C. Prägnanzbildung. In: KÖHNKE, K. C. et al. Prägnanzbildung und Ästhetisierung in Bildangeboten und Bildwahrnehmungen; Leipzig, Leipziger Universitätsverlag, 2001.

KRAUSHAAR, W. Radikalisierung der Mitte. Auf dem Weg zur Berliner Republik. In: FABER, R. u. a. (Hrsg.). Rechtsextremismus. Ideologie und Gewalt. Berlin: Edition Hentrich, p. 52-69, 1995.

HUHNKE, B. Intermediale Abhängigkeiten bei der Inszenierung rassistischer Feindbilder seit Mitte der achtziger Jahre am Beispeil der Wochenzeitungen "Bild am Sonntag" und "Der Spiegel". In: JÄGER, S.; LINK, J. (Hrsg.). Die vierte Gewalt. Rassismus und die Medien. Duisburg: Diss, 1993, p. 213-266.

HOLZKAMP, K. Grundlegung der Psychologie. FrankfurtM; New York: Campus Verlag, 1985.

Latitude, Vol. 1, n'2, pp.47-65, 2007. 
LEIPRECHT, R. “...da baut sich ja in uns ein Hass auf...". Zur subjetiven Funktionalität von Rassismus und Ethnozentrismus bei abhaengig beschaeftigten Jugendlichen. Hamburg/Berlin: Argument, 1990.

LEONTJEW, A. N. Tätigkeit, Bewusstsein, Persönlichkeit. Köln: Pahl-Rugenstein, 1982.

LINK, J. Grenzen des flexiblen Normalismus? In: SCHULTE-HOLTEY, E. Grenzmarkierungen. Normalisierung und diskursive Ausgrenzung. Duisburg: Diss, p. 24-39, 1995.

OSTERKAMP, U. Rassismus als Selbstentmächtigung. Berlin/Hamburg: Argument, 1996.

OSTERMANN, Ä. Zur Analyse aussenpolitisch relevanter Feindbilder in der Bundesrepublik 1949-1971. Das Freund-Feind-Schema als stereotypes Perzeptionsmuster internationaler Politik. Zum Problem stereotyper Muster in der Darstellung von Geschichte und Politik. [Dissertation]. Frankfurt am Main: Johann Wolfgang Goethe-Universitaet, 1977.

PETERSEN, T.; SHWENDER, C. Visuelle Stereotypen. Köln: Herbert von Halem Verlag, 2009.

PFENNIG, J. Krawallos, Kids und dumme Jungs. In: SchlagZeilen. Rostock: Rassismus in den Medien. Diss-Skripten n'. 5. Duisburg: Diss, 1993.

PROJEKT IDEOLOGIE-THEORIE (PIT). Theorien über Ideologie. Berlin: Argument, 1986.

QUINKERT, A; JÄGER, S. Die rassistische Hetze von Bild gegen Füchtlinge im Herbst 1991. Duisburg: Diss, 1991.

RADTKE, F. O. Lob der Gleich-Gültigkeit. Die Konstruktion des Fremden und die Wirklichkeit des Imaginären. In: BIELEFELD (Hrsg.). Das Eigene und das Fremde. Neuer Rassismus in der alten Welt? Hamburg: Junius, p. 79-96, 1991.

SANTOS, B. S. A crítica da razão indolente. Contra o desperdício da experiência. São Paulo: Cortez, 2007.

SARTRE, J. P. Réflexions sur la question juive. Paris: Gallimard, 1954.

SCHÄFER, B. ; SIX, B. Sozialpsychologie des Vorurteils. Stuttgart: Kohlhammer, 1978.

SATJUKOW, S.; GRIES, R. Feindbilder des Sozialismus. Eine theoretische Einführung. In: SATJUKOW, S.; GRIES, R (Hg.): Unsere Feinde. Konstruktionen des Anderen im Sozialismus. Leipzig, Leipziger Universitätsverlag, 2004.

SEYFARTH, R. Feindbildkonstruktion. Strategische Visualisierung einer Verknüpfung von "Anders \& Hässlich". Leipzig: Universitaet Leipzig, 2006.

SKINNER, B. F. Verbal Behavior. New York: Appleton-Century-Crofts, 1957.

Latitude, Vol. 1, n², pp.47-65, 2007. 
SOARES DO BEM, A. Kreuzberger Jugendliche zwischen Revolte und Autoritarismus. Das Argument, Berlim/Hamburg, no 191, p. 79-84, 1992.

- Educação e Reprodução do Racismo: As armadilhas dos modelos "alternativos". Revista Educação \& Sociedade. Ano XIV, n 44, Campinas: Papirus, p. 96-110, 1993a.

. Para uma crítica da Política de Integração da segunda geração de "estrangeiros" na Alemanha. Comunicação \& Política na América Latina. Ano XI n ${ }^{\circ}$ 17. São Paulo: Centro Brasileiro de Estudos Latino Americano, p. 91-108, 1993b.

- Erziehung und Reproduktion rassistischer Denkweise: Die Fallstricke alternativer Modelle. In: Wagner, Silvia; Nuetzel, Gerdi; Kick, Martin. (Org.). Anti-Rassistische Irritationen - Biblische Texte und interkulturelle Zusammenarbeit. 1 ed. Berlim: Alektor Verlag Berlin, Vol.: 1, p. 201-215, 1994a.

. Cultura, política e racismo. In: Revista Princípios, $n^{\circ} 34$. São Paulo: Editora Anita Ltda., p. 44-51, 1994 b.

Das Spiel der Identitaeten in der Konstitution Von "Wir"-Gruppen: ost-und westdeutsche Jugendliche und in Berlin geborene Jugendliche auslaendischer Herkunft im gesellschaftlichen Umbruch. Frankfurt/M, Berlin, Bern, New York, Paris, Wien: Peter Lang, 1998.

A insustentável identidade dos Skinheads tropicais: uma abordagem sociológica. In: Ângela Maria Benedita B. de Brito, Moisés de Melo Santana e Rosa L. S. Correia. (Org.). Educação e identidade negra. 1 ed. Maceió: Edufal, 2005, Vol.: 1, p. 100-115, 2005.

Discurso, ideologia e violência entre jovens de várias origens nacionais na Alemanha durante o processo de unificação. In: Cenários da Comunicação, Vol. 7, $\mathrm{n}^{\circ}$ 1. São Paulo: Uninove, p. 39-45, 2008a.

. Dominação da subjetividade e repressão à religiosidade africana no Brasil: uma praxis transatlântica secular. In: Cavalcanti, B. et al. (Org.). Religiões afrobrasileiras. Maceió: Edufal, 2008, p. 69-86, 2008b.

- Igreja, Estado e ciência como espaços de interpelação e repressão à religiosidade africana no Brasil. In: Anais do III Simpósio Internacional sobre religiosidades, diálogos culturais e hibridações. Campo Grande: Universidade Federal de Mato Grosso do Sul, p. 1-9, 2009.

VAN DIJK, T. A. Rassismus heute: der Diskurs der Elite und seine Funktion für die Reproduktion des Rassismus. Diss-Texte n 14. Duisburg : Diss, 1991.

WAGENLEHNER, G. (Hg.). Feindbild. Geschichte, Dokumentation, Problematik. Frankfurt/Main: Report, 1989.

Latitude, Vol. 1, n², pp.47-65, 2007. 
WAGNER, U. Soziale Schichtzugerörigkeit, formales Bildungsniveau und ethnische Vorurteile. Unterschiede in den kognitiven Fähigkeiten und der sozialen Identität als Ursachen für Differenzen im Urteil über Türken. Eine empirische Untersuchung. Berlin: Express-Edition, 1982.

WALLRAFF, G. Ganz unten. Köln: Verlag Kiepenheuer \& Witsch, 1985.

WICHERT, F. Die konjunkturelle Entwicklung des Themas Azyl im Deutschen Bundestag. In: SCHULTE-HOLTEY, E. Grenzmarkierungen. Normalisierung und diskursive Ausgrenzung. Duisburg: Diss, 1995.

WICHERT, F. Im wilden Osten. Rostock als Problem der Ostdeutschen. In: SchlagZeilen. Rostock: Rassismus in den Medien. Diss-Skripten, $\mathrm{n}^{\circ}$ 5. Duisburg: Diss, 1993.

Latitude, Vol. 1, n², pp.47-65, 2007. 